\title{
AS CONTRIBUIÇÕES DO PENSAMENTO WALLONIANO EM INTERVENÇÕES PSICOPEDAGÓGICAS
}

\author{
Tharcila Damaceno ${ }^{1}$ \\ Instituto Sedes Sapientiae, São Paulo, SP, Brasil
}

\section{RESUMO}

Este artigo tem por objetivo reunir os principais aspectos do pensamento walloniano acerca do desenvolvimento humano a fim de constituir um diálogo com a prática psicopedagógica. Inicialmente, busca-se explicitar a centralidade da dimensão afetiva no processo de ensino-aprendizagem, pressuposto que é fundamentado a partir dos cinco estágios do desenvolvimento, caracterizados por Wallon como etapas que apontam o caráter dialético e não-linear da aprendizagem a ser considerado pela Psicopedagogia. À luz do pensamento walloniano, aborda-se a motricidade e emoção como componentes relevantes do trabalho psicopedagógico. Faz-se também uma breve contextualização histórica sobre os dilemas atuais enfrentados no campo da Educação.

Palavras-chave: pensamento walloniano, Psicopedagogia, processo de aprendizagem.

\footnotetext{
${ }^{1}$ Professora de Educação Física (UNIFIEO), pós-graduanda em Psicopedagogia (Instituto Sedes Sapientiae), bacharel em Educação Física (FEFISA).
} 


\title{
THE CONTRIBUTIONS OF WALLONIAN THOUGHT IN PSYCHO-PEDAGOGICAL INTERVENTIONS
}

\begin{abstract}
This article aims to bring together the main aspects of Wallonian thinking about human development in order to constitute a dialogue with psychopedagogical practice. Initially, we seek to clarify the centrality of the affective dimension in the teaching-learning process, an assumption that is based on the five stages of development, characterized by Wallon as steps that point to the dialectical and non-linear character of learning to be considered by the Psychopedagogy. In the light of Wallonian thinking, motricity and emotion are addressed as relevant components of psychopedagogical work. There is also a brief historical contextualization about the current dilemmas faced in the field of Education.
\end{abstract}

Keywords: wallonian thinking, Psychopedagogy, pearning process.

\section{Introdução}

Este artigo tem por objetivo reunir os principais aspectos do pensamento walloniano acerca do desenvolvimento humano a fim de constituir um diálogo com a prática psicopedagógica. Para tanto, além desta breve introdução, o artigo está dividido da seguinte forma:

Na primeira seção do presente artigo, A dimensão afetiva da aprendizagem, se apresentam as duas principais contribuições de Wallon para a Psicopedagogia, quais sejam: a centralidade da afetividade no processo de desenvolvimento integral do indivíduo e a importância do conhecimento do meio sociocultural do qual o sujeito participa e com o qual interage. Dessa forma se busca demonstrar como a relação entre psicogênese e sociogênese é um ponto de partida fundamental para essa abordagem psicopedagógica.

Na segunda seção, por sua vez, As etapas da psicogênese segundo Wallon, descrevem-se os cinco estágios do processo de aprendizagem: impulsivo-emocional, sensório motor e projetivo, personalismo, categorial e puberdade e adolescência. Busca-se, dessa forma, problematizar o dualismo entre processos cognitivos e processos motores e afetivos, bem como suas direções centrípetas e centrífugas, além dos diferentes ritmos e intensidades de aprendizagem.

Na terceira seção, por seu turno, Afeto e emoção no processo psicopedagógico, se apresenta a diferenciação conceitual entre afetividade e emoção; já na quarta seção, $O$ corpo $e$ a prática psicopedagógica, se estabelecem as relações práticas entre afetividade e motricidade; na quinta seção, por fim, O brincar como ferramenta de aprendizagem, os jogos e brincadeiras são apresentados como instrumentos psicopedagógicos potenciais para a atuação nessa área de contato walloniana entre mente e corpo. Por fim, apresentam-se algumas conclusões sobre a utilização dessas referências em um contexto de mudanças sociais e educacionais.

A partir do roteiro sintético descrito acima, o artigo apoia-se em Wallon para pensar a Psicopedagogia como construção de uma visão humanizada sobre o processo de desenvolvimento dos 
seres humanos, baseada numa lógica de movimento e não de fixações. Compreender a pessoa integral e completa, ou seja, a partir de suas relações sociais e da integração de seus conjuntos funcionais: motor, cognitivo e socioafetivo, é o ponto de partida para definir os valores e os caminhos singulares a serem desenvolvidos no atendimento psicopedagógico.

Nesse sentido, defende o artigo, o pensamento walloniano talvez possa ser uma forma de resistência à tendência ocidental dualista que privilegia os processos cognitivos, em detrimento de uma relação horizontal entre cognição, afetividade e motricidade.

\section{A Dimensão Afetiva da Aprendizagem}

A primeira e grande contribuição da teoria walloniana para a Psicopedagogia é a centralidade da afetividade no processo de desenvolvimento integral do indivíduo. Seguindo a foturna crítica walloniana, Mahony \& Almeida (2005) interpretam a afetividade como a capacidade e a disposição do ser humano de ser afetado pelo mundo externo e interno por sensações ligadas a tonalidades agradáveis ou desagradáveis. Ferreira \& Acioly-Régner (2010, p.27) ampliam esta definição tratando a afetividade "como um conjunto funcional que emerge do orgânico e adquire um status social na relação com o outro e que é uma dimensão fundante na formação da pessoa completa."

Tendo em vista isso, toda intervenção psicopedagógica deve enfatizar e trabalhar a dimensão afetiva do sujeito a partir do estabelecimento de vínculos, do acolhimento e da busca constante por vivências prazerosas. Um ambiente acolhedor e que promova o bem-estar do paciente favorece a construção e o fortalecimento da sua identidade e da sua autoestima. Portanto, para além das limitações identificadas ou relatadas por parte daqueles que se relacionam com o sujeito, é fundamental que o eixo do atendimento seja a valorização do indivíduo em sua integralidade, impedindo que ele seja reduzido ao desenvolvimento de sua intelectualidade ou ao seu problema de aprendizagem.

Cabe considerar que a afetividade é uma dimensão presente tanto da parte do atendido quanto do psicopedagogo, ou seja, num processo terapêutico ambos os envolvidos são afetados mutuamente. Ao psicopedagogo é conferida a tarefa de zelar pelo o que emana e se apresenta emocionalmente ao paciente, que naturalmente será contagiado por aquilo que vivencia. Na mesma proporção, deve-se estar sensivelmente atento aos sinais corporais que apontam a forma como o sujeito está experimentando as intervenções propostas. Sensações agradáveis, de acolhimento e de receptividade são perceptíveis e devem servir para dar o tom de um atendimento favorável. Aprende-se (e se ensina) sentindo o outro.

Wallon também contribui para a Psicopedagogia quando interpreta a noção de sujeito como uma coletânea de influências sociais e fisiológicas. Segundo Moraes \& Oncalla (2011, p.215) o autor francês entende que "o indivíduo é geneticamente social, humaniza-se e individualiza-se nas relações com os outros indivíduos". Os aspectos orgânicos e sociais a serem considerados pelo psicopedagogo em suas intervenções demandam um olhar ampliado e atento à complexidade do sujeito e à sua contextualização. Sendo assim, uma segunda função indispensável para o atendimento é ter conhecimento do meio ao qual o sujeito participa e interage. Analisar a sua cultura familiar, a escola que frequenta, outras possíveis instituições da qual faz parte, assim como a realidade social em que está inserido é fundamental. Também é de extrema importância avaliar qualitativamente as relações vivenciadas, as possibilidades ofertadas, o histórico de vida e as atividades diárias que fazem parte da constituição do sujeito a ser atendido. 
Neste sentido, apoiar-se em Wallon para pensar a Psicopedagogia é construir uma visão humanizada sobre o processo de desenvolvimento dos seres humanos, baseada numa lógica de movimento e não de fixações. Compreender a pessoa integral e completa, ou seja, a partir de suas relações sociais e da integração de seus conjuntos funcionais: motor, cognitivo e afetivo, é o ponto de partida para definir os valores e os caminhos singulares a serem desenvolvidos no atendimento psicopedagógico.

Após esse traçado introdutório, onde afirmou-se duas grandes tarefas imprescindíveis à Psicopedagogia - a importância de se pensar a afetividade estabelecendo vínculos e de se contextualizar o paciente respeitando sua integralidade e singularidade - é importante destrinchar outros conceitos relevantes trazidos pelo pensamento walloniano.

\section{As Etapas da Psicogênese segundo Wallon}

Para o autor a aprendizagem é um processo não linear, que se caracteriza por uma relação dialética, de oscilações entre a afetividade e a inteligência. E que também "apresenta movimentos que implicam integração, conflitos e alternâncias na predominância dos conjuntos funcionais" (Ferreira \& Acioly-Régner, p. 29).

Este fenômeno ocorre constantemente em todo o processo de desenvolvimento do indivíduo e que é definido por cinco estágios:

- 10 estágio - impulsivo-emocional ( 0 - 1 ano): predominantemente afetivo, onde a expressão se dá por meio dos movimentos corporais, do contato corporal e do toque. Nesta etapa a interação com o ambiente se dá pela fusão com o outro, através do toque, do tato e da segurança do embalo;

- 20 estágio - sensório-motor e projetivo ( 1 - 3 anos): predominantemente cognitivo, caracterizado pela relação intensa do sujeito com os objetos. Nesta etapa é fundamental que a criança tenha a maior quantidade possível de experiências em diferentes espaços e situações diversificadas, pois a partir daqui iniciará o processo de diferenciação entre os objetos e vivências;

- 3o estágio - personalismo (3 - 6 anos): predominantemente afetivo, caracterizado pelo estágio em que a criança descobre que é diferente do outro. Nesta etapa é importante que a criança vivencie experiências que possibilitem o exercício da escolha e do convívio com outras idades. Ao psicopedagogo ou educador, é desejável que as intervenções privilegiem a expressão destas diferenças identificadas pela criança;

- 4 estágio - categorial (6 - 11 anos): predominantemente cognitivo, é o estágio em que as diferenças com o outro ficam mais intensas e nítidas. Nesta etapa as diferenças e as semelhanças entre objetos, imagens, conceitos e ideias passam a ser bastante explorados. No sentido educacional, ou psicopedagógico, é interessante ofertar grande variedade de experiências afetivas, que desenvolvam sentimentos e valores que favoreçam a continuidade dessas descobertas;

- 50 estágio - puberdade e adolescência (11 anos em diante): predominantemente afetivo, onde prevalece o desejo de se diferenciar e ganhar autonomia. Nesta etapa os valores e os sentimentos próprios ficam em evidência por meio dos confrontos e da autoafirmação. Dentro do trabalho psicopedagógico é importante criarmos espaço de expressão e discussão sobre essas diferenças e descobertas, propondo relações de respeito mútuo e solida- 
riedade. Atividades mais elaboradas também são bem-vindas, visto que neste estágio já se apresenta a noção de reversibilidade, de análise e de síntese.

Estes estágios podem servir como ferramenta em possíveis intervenções psicopedagógicas e educacionais, onde há de se considerar não somente a faixa etária, mas o mundo concreto em que o sujeito transita (externa e internamente). De acordo com Mahony \& Almeida (2005, p.15) esta é uma teoria que assume três funções paralelas e complementares: "dá previsibilidade à rotina, oferece subsídios para o questionamento e o enriquecimento da prática e da própria teoria, possibilita alternativas de ação com maior autonomia e segurança ".

Em especial deve se estar atento ao pensamento flexível, que não leve à risca o tempo cronológico e teleológico característico da nossa cultura ocidental, que tende a racionalizar todos os processos, sempre os colocando de maneira hierarquizada.

Ao contrário do que propõe a tradição intelectualista do ensino, uma pedagogia inspirada na psicogenética walloniana não considera o desenvolvimento intelectual como a meta máxima e exclusiva da educação. Considera-a, ao contrário, meio para a meta maior do desenvolvimento da pessoa, afinal, a inteligência tem status de parte no todo constituído pela pessoa. (GALVÃO, 2007, p. 98).

Portanto, seria o pensamento walloniano uma forma de resistência a esta tendência ocidental dualista que privilegia os processos cognitivos, visto que ele estabelece uma relação horizontal da cognição para com a motricidade e a afetividade?

Ao atribuir ao corpo, ao movimento e às emoções um papel relevante, que pode e deve ser explorado em todo o percurso da vida humana, Wallon nos aponta um caminho de infinitas possibilidades para os mais diversificados tempos, espaços e trajetórias. E a despeito de uma cultura que suprime a afetividade em detrimento da racionalidade, o autor naturaliza ambos os fenômenos como acontecimentos importantes e inerentes à vida.

Mais do que abordar a afetividade e a inteligência de acordo com cada estágio do desenvolvimento, as contribuições wallonianas podem nos apoiar em relação à direção em que o sujeito se encontra: centrípeta, quando está mais voltado para o conhecimento de si mesmo, ou centrífuga, quando está mais voltado para o conhecimento do mundo exterior.

Identificar se o paciente está mais autocentrado ou mais sugestionado ao mundo exterior é fundamental para propormos atividades mais coerentes com suas necessidades e potencialidades. Ou seja, num estágio predominantemente afetivo, o foco está na construção do sujeito a partir suas interações interpessoais (da pessoa para o outro), enquanto num estágio cognitivo a tendência é cultural (da pessoa para com o objeto), onde entram em foco as técnicas elaboradas pela cultura. Ter ciência disso traz um caráter mais singular e personalizado ao atendimento psicopedagógico.

Uma outra característica importante da teoria walloniana é a compreensão das possíveis regressões entre os estágios como parte natural do processo de desenvolvimento dos sujeitos. O olhar de Wallon para essa tendência não linear é brando e a não enxerga como uma defasagem incontornável. A mescla entre os fatores orgânicos e os fatores sociais definem um ritmo de desenvolvimento com encavalamentos e sobreposições. Um movimento descontínuo e assistemático, com reformulações constantes. Contrapondo-se à visão estruturalista piagetiana, Wallon considera os recuos e os retrocessos como parte do processo de aprendizagem.

Da mesma forma existe leveza no olhar para a patologia, definindo-a como um processo que apresenta um ritmo mais lento e mesmo intenso de desenvolvimento. Portanto, uma valiosa contribuição do autor para a prática psicopedagógica é a certeza de que todos os seres humanos são seres em desenvolvimento, mas com diferentes ritmos e intensidades. 
Ao psicopedagogo caberia então a complexa tarefa de promover interações e explorar novos patamares de evolução, que não esbarrem numa visão limitada e eugenista, fundamentada numa lógica de desempenho e competitividade a partir da funcionalidade dos sujeitos.

\section{Afeto e Emoção no Processo Psicopedagógico}

Retomando a afetividade, ainda podemos nos debruçar sobre a diferenciação que Wallon faz entre afetividade e emoção. Para melhor entendimento, é preciso que tenhamos em conta que dentro do olhar walloniano a afetividade e a emoção não são sinônimas.

Uma das contribuições centrais de Wallon está em dispor de uma conceituação diferencial sobre emoção, sentimentos e paixão, incluindo todas essas manifestações como um desdobramento de um domínio funcional mais abrangente: a afetividade, sem, contudo, reduzi-los uns aos outros (Ferreira \& Acioly-Régner, 2010, p.26).

O autor sugere que a emoção é uma linguagem antes da linguagem, mais arcaica e reativa, enquanto a afetividade é mais abrangente. A emoção é, portanto, a forma mais expressiva da afetividade, um mecanismo de sobrevivência da espécie humana com predominância orgânica.

Para Wallon a emoção tem um papel central na constituição do indivíduo, mas ela não pode ser observada isoladamente visto que sempre está intimamente atrelada à dimensão cognitiva, corporal e social do sujeito. O papel da emoção encontra dois sentidos opostos e complementares, um voltado ao mundo externo do sujeito que diz respeito à motricidade emocional, e outro voltado ao mundo interno do sujeito, através da representação, que diz respeito à sensibilidade emocional. Como afirma Alexandroff (2012: p.37):

Assim, a emoção oscilaria entre duas formas de relação do homem com o meio. A primeira, a motricidade emocional, permite a reação às situações externas, utilizando-se de movimentos apropriados, auxiliando a criança no seu relacionamento com o meio físico e social. A segunda, a sensibilidade emocional, permite conceituar o mundo físico internamente, através da representação, transformando-o conforme as necessidades do sujeito ou de seu grupo.

Em suma, a emoção é a expressão ou atitude diante de uma situação, necessariamente decorrida de uma função postural que corresponde a variações viscerais e musculares do tônus.

O sentimento, por sua vez, também está presente no campo da afetividade, tem um caráter representativo que não envolve necessariamente uma reação direta e rápida, além de poder inclusive dominar e autocontrolar as emoções. Assim, "ao longo do desenvolvimento, a afetividade vai adquirindo independência dos fatores corporais, passando a ser expressa por palavras e outras manifestações, sem a necessidade de alterações corporais visíveis" (ALEXANROFF, 2012, p. 38). Fenômeno que só pode ser observado por volta dos três anos de idade, representado por exemplo pelos ciúmes, pelas exigências e pelo desejo de exclusividade.

\section{O Corpo e a Prática Psicopedagógica}

Wallon também se dedicou ao estudo da motricidade e do movimento atribuindo à atividade muscular duas funções elementares: a cinética e a postural. A atividade cinética, também nomeada como clônica, diz respeito ao movimento corporal no espaço enquanto a atividade postural ou tônica representa a manutenção da posição assumida, ou seja, a ausência do movimento sustentado pela musculatura. Em outras palavras, "a musculatura possui duas funções: a função 
cinética, que regula o estiramento e o encurtamento das fibras musculares, e é responsável pelo movimento propriamente dito; e a função postural ou tônica, que regula a variação no grau de tensão (tônus) dos músculos" (GALVÃO, 2007, p. 69).

Os movimentos por sua vez são classificados a partir do centro de controle e podem ser reflexos, quando controlados ao nível medular, involuntários, quando controlados pelo sistema extrapiramidal em nível subcortical, ou voluntários, quando controlados pelo sistema piramidal em nível cortical.

Numa sequência psicogenética os movimentos impulsivos (globais e incoordenados) são os primeiros a surgirem, até volta de 3 meses de idade, quando então aparecem os movimentos expressivos, dos 3 meses até um ano, e os movimentos instrumentais (práxicos), entre 6 meses e um ano. A predominância práxica da motricidade chega no período sensório-motor, quase em concomitância com a predominância simbólica e semiótica, quando as ideias são projetadas em mímica, fala e/ou escrita. A trajetória do desenvolvimento infantil à luz da motricidade passa dos gestos simbólicos, para o processo ideativo até entrarem num processo de internalização, onde as sincinesias diminuem. Entendendo as sincinesias a partir de Galvão (2007, p. 74), "como os movimentos desnecessários que 'parasitam' uma praxia, perturbando sua realização adaptada."

O pensamento walloniano identifica um caráter afetivo na motricidade, caracterizado no movimento através de sua dimensão expressiva. Também é identificada no movimento uma mentalidade projetiva, quando um ato mental projeta um ato motor, quando "o gesto precede a palavra", como afirma Galvão (2007, p.72).

O protagonismo do movimento na aprendizagem confere ao pensamento walloniano um lugar especial na Psicopedagogia, área que atribui ao desenvolvimento da corporeidade um papel fundamental na construção da pessoa. Através do corpo e do movimento o acesso ao campo da afetividade se faz possível, juntamente com a emoção, qualificando o processo terapêutico de forma a conduzir o sujeito para espaços inabitados do seu próprio ser.

Em outras palavras, as contribuições de Wallon acerca do papel do corpo no processo de desenvolvimento dos sujeitos pode ser apropriado pela Psicopedagogia como uma forma de qualificação da existência tanto do psicopedagogo quanto do indivíduo em atendimento, em especial no que tange os processos de aprendizagem.

O que propõe o pensamento walloniano, em certa medida, é resistir ao modelo disciplinar de submissão dos corpos em favor da mente, subvertendo a hierarquia dualista que opõe a dimensão cognitiva da dimensão afetiva de um sujeito, colocando o movimento como um elemento fundamental para a aquisição dos demais aspectos do desenvolvimento da criança.

\section{O Brincar Como Ferramenta da Aprendizagem}

Wallon afirma que o ato precede o pensamento até chegar à representação, que por sua vez é possibilitada pela linguagem:

"[...] do ato motor à representação houve transposição, sublimação desta intuição que, de incluída nas relações entre o organismo e o meio físico, se tornou esquematização mental. A evolução ocorrida entre $\mathrm{o}$ ato e o pensamento explica-se simultaneamente pelo oposto e pelo mesmo." (WALLON, 2008, p. 224). 
Neste momento o sujeito é capaz de resolver problemas de ordem concreta. A partir de então o ato motor vai dando espaço para a atividade cognitiva, por meio da simbolização. As disciplinas mentais, definidas pelo controle do sujeito sobre suas próprias ações é um fenômeno que pode ocorrer entre os 6 ou 7 anos de idade e que é possibilitado pelas condições neurológicas, pela aquisição da linguagem e do conhecimento.

Como característica as crianças passam a gozar de ocupações mais dirigidas e não somente daquelas espontâneas. Sendo assim, os educadores e psicopedagogos precisam de bastante habilidade para não gerarem um efeito de instabilidade no processo de aprendizagem, onde imperariam a monotonia e a falta de interesse. As atividades e intervenções propostas devem ser envolventes a ponto de gerarem um efeito de perseverança.

Desta forma, um exercício interessante a ser pensado como prática psicopedagógica seria a possibilidade a manutenção constante do movimento pendular entre simbolização e ato motor, transitando entre corpo agitado ou relaxado, corpo enrijecido e corpo harmonizado. Possivelmente através de diferentes estímulos a prática psicopedagógica pode ser prazerosa e manter o paciente num estado de bem-estar, sempre presentificado, em contato ampliado com a sua corporeidade.

Identificar necessidades e urgências corporais é uma tarefa a ser desenvolvida tanto pela sensibilização de quem media o processo de ensino-aprendizagem, aqui personificado no psicopedagogo, quando quem o protagoniza.

Uma boa sugestão para os atendimentos psicopedagógicos, a partir do pensamento de Wallon, é a utilização de brincadeiras e jogos. $\mathrm{O}$ autor define o jogo como uma atividade voluntária da criança, classificando-o em quatro tipos:

- Funcional: atividades corporais, ações gestuais que exploram e desenvolvem a motricidade;

- Fiç̧ão: brincadeiras de "faz de conta", que transitam entre a ficção e a observação do meio;

- Aquisição: imitações que auxiliam no conhecimento e compreensão da realidade;

- Fabricação: atividades manuais, que transitam entre a matéria e o imaterial (vida fictícia).

Por meio das atividades psicopedagógicas podemos ampliar o repertório das crianças, observando como agem e como lidam com o que vivenciam. $O$ jogo nos possibilita identificar e trabaIhar a agressividade, a competição, o ganhar e o perder, a inveja, a rivalidade, o sentimento de inferioridade ou superioridade, o sentimento de amor e de ódio. É pelo jogo que a criança pode sentir, pensar e se movimentar, assim como pode passar a perceber com mais clareza a causa e o efeito de suas ações.

Cabe também salientar que por meio dos jogos podemos não apenas trabalhar as emoções, mas naturalizá-las. Dentro de um molde social que castra e tende a patologizar comportamentos emotivos, situando-os como sintomas e não como aspectos inerentes ao ser humano, o brincar por meio do jogo cria espaços de liberação, autoconhecimento e de transgressão da domesticação do sentir.

No caso dos pacientes que estão transitando do estágio categorial para o estágio da puberdade e adolescência, a Psicopedagogia pode se valer de atividades de classificar, categorizar, compreender e representar, sempre buscando integrar as três dimensões psíquicas do sujeito (motora, afetiva e cognitiva), desde que elas estejam de acordo com as condições apresentadas 
pelo sujeito. Caso as propostas não estejam dentro das possibilidades do sujeito, possivelmente se notará um estado de imperícia e crise, remetendo o exercício a uma reação puramente emocional, sem apresentar clareza do raciocínio.

\section{Considerações finais: Dilemas do Processo de Ensino Contemporâneo}

É importante considerar que o pensamento walloniano foi desenvolvido na primeira metade do século XX, no processo de consolidação da sociedade urbana industrial. Atualmente vivemos uma mudança estrutural na nossa sociedade, estamos vendo despontar um mundo digital que nos afasta das vivências corporais em benefício de experiências virtualizadas e que demandam um ritmo, social e orgânico, que nos desumaniza.

Incorporar e intensificar as ações práticas, materializadas nos atos motores e na afetividade, valores caros à teoria walloniana, é conceder aos aprendentes o direito ao seu desenvolvimento integral.

A Psicopedagogia deve ter como premissa o acolhimento dos sujeitos e a promoção dos caminhos que favorecem a constituição da pessoa, este ser integral, social e que está submetido aos processos afetivos e cognitivos, sempre pelo intermédio do corpo e da motricidade.

Dentro de uma perspectiva walloniana a aprendizagem deve estar imbuída de interações sociais, trocas e formação de vínculos, proporcionando mecanismos de compreensão, aceitação, negação, assimilação, defesa ou administração das sensações e sentimentos desencadeados. Portanto, para a prática psicopedagógica os conceitos wallonianos são valiosos e oferecem ensinamentos essenciais sobre o olhar cauteloso e cuidadoso para com os seres aprendentes.

A despeito de uma educação que tende a disciplinar corpos por meio da castração e submissão dos desejos e dos impulsos, Wallon nos oferece através de suas teorias a utopia esperançosa de sermos um todo, sem fragmentações. Esta visão monista dos seres favorece a recuperação e integração de tempos e espaços, materiais e imateriais, corpóreos e incorpóreos, individuais e coletivos. E numa sociedade onde a ditadura do desempenho tende a gerar indivíduos fracassados e depressivos, beber de Wallon é um alento para os educadores que defendem a emancipação dos sujeitos.

\section{Referências}

ALMEIDA, L. R \& MAHONEY A. A. Afetividade e processo de ensino-aprendizagem: contribuições de Henri Wallon. São Paulo, Edições Loyola, 2007.

ALEXANDROFF, M. C. - Emoção e escrita: fios que se unem numa mesma trama. Tese de Mestrado, FEUSP, 1998.

ALEXANDROFF, M. C. - O Papel das emoções na constituição do sujeito. Constr. psicopedag., 2012, vol.20, no.20, p.35-56. ISSN 1415-6954

FERREIRA, A.L. \& ACIOLY-RÉGNER, N.M. Contribuições de Henri Wallon à relação cognição e afetividade na educação. In: Educar, Curitiba, n.36, p. 21-28, 2010.

GALVÃO, I. - Henri Wallon - uma concepção dialética do desenvolvimento infantil. Petrópolis, Vozes, 2007. 
WALLON, H. Do ato ao pensamento: ensaio de psicologia comparada. Petrópolis: Vozes, 2008.

WALLON, H. - Psicologia e educação da infância. Lisboa, Estampa, 1975.

Wallon, H. O papel do outro na consciência do Eu. In M. J. Werebe, \& J. Nadel-Brulfert (Orgs.), Henri Wallon (pp.158-167). São Paulo: Ática, 1986. 